\title{
Syngeneic murine glioblastoma models: reactionary immune changes and immunotherapy intervention outcomes
}

\author{
Vijay Letchuman, BA, ${ }^{1}$ Leonel Ampie, MD, ${ }^{1,2}$ Ashish H. Shah, MD, ${ }^{1}$ Desmond A. Brown, MD, PhD, ${ }^{1}$ \\ John D. Heiss, MD, ${ }^{1}$ and Prashant Chittiboina, MD1
}

${ }^{1}$ National Institute of Neurological Disorders and Stroke, National Institutes of Health, Bethesda, Maryland; and 2Department of Neurological Surgery, University of Virginia Health System, Charlottesville, Virginia

\begin{abstract}
Glioblastoma is the most common primary malignant brain neoplasm with dismal 10 -year survival rates of $<1 \%$. Despite promising preliminary results from several novel therapeutic agents, clinical responses have been modest due to several factors, including tumor heterogeneity, immunosuppressive tumor microenvironment, and treatment resistance. Novel immunotherapeutics have been developed to reverse tumor-induced immunosuppression in patients with glioblastomas. In order to recapitulate the tumor microenvironment, reliable in vivo syngeneic murine models are critical for the development of new targeted agents as these models demonstrate rapid tumor induction and reliable tumor growth over multiple generations. Despite the clear advantages of murine models, choosing an appropriate model from an immunological perspective can be difficult and have significant ramifications on the translatability of the results from murine to human trials. Herein, the authors reviewed the 4 most commonly used immunocompetent syngeneic murine glioma models (GL261 [C57BL/6], SB28 [C57BL/6], CT-2A [C57BL/6], and SMA-560 [VM/Dk]) and compared their strengths and weaknesses from an immunological standpoint.
\end{abstract}

https://thejns.org/doi/abs/10.3171/2021.11.FOCUS21556

KEYWORDS glioblastoma; murine; immunotherapy

$\mathrm{O}$ UTCOMES for patients with glioblastoma (GBM), the most common primary malignant brain neoplasm, remain poor with a median survival of 15 months..$^{1-4}$ The current standard of care involves maximal safe resection followed by the Stupp protocol, which consists of radiation therapy and concurrent temozolomide (TMZ) with subsequent adjuvant TMZ monotherapy. Despite these interventions, tumors recur in most patients within 6 months. ${ }^{5}$ Due to the promising results of immune checkpoint blockade treatment of systemic cancers, targeted immunotherapeutic agents against GBM have gained traction.

Despite promising clinical results in a variety of other cancers, immunotherapy for GBM has had a modest clinical effect in large clinical trials. The immunosuppression posed by the local tumor microenvironment is well known; however, the systemic effects of this microenvironment have yet to be thoroughly characterized. Patients with GBM exhibit profound systemic immunosup- pression with CD4+ T-cell levels, comparable to patients with acquired immunodeficiency syndrome (AIDS). ${ }^{6-8}$ This lymphopenic event was recently demonstrated to be secondary to lymphocytic sequestration in the bone marrow rather than cytolytic activity. ${ }^{8}$ Furthermore, early studies have suggested that GBM releases factors such as programmed death-ligand 1 (PD-L1) and extracellular vesicles that contribute directly to its immunosuppressive phenotype. Another immunosuppressive component of GBM is that tumors are often infiltrated by tumor-associated macrophages (TAMs) of the M1 or M2 phenotype. M1 macrophages are associated with direct tumoricidal activity through a type 1 immune response. However, M2 macrophages maintain an immunosuppressive phenotype and promote tumor growth while suppressing the type 1 immune response. ${ }^{9-11}$ Other immunoevasive mechanisms include an upregulation of regulatory $\mathrm{T}$ cells $\left(\mathrm{T}_{\mathrm{reg}}\right)$ in the periphery, as well as low expression of major histocompatibility complex (MHC) class I molecules. ${ }^{1,6}$

ABBREVIATIONS ASO = antisense oligonucleotide; BTSC = brain tumor stem cell; CTLA-4 = cytotoxic T-lymphocyte associated protein 4; GBM = glioblastoma; GFAP = glial fibrillary acidic protein; $\mathrm{MHC}=$ major histocompatibility complex; NHE1 = sodium/hydrogen exchanger $1 ; \mathrm{PD}-1$ = programmed cell death protein $1 ; \mathrm{PD}-\mathrm{L} 1$ = programmed death-ligand $1 ; \mathrm{PDX}=$ patient-derived xenograft; $\mathrm{SB}=$ Sleeping Beauty; $\mathrm{TAM}=$ tumor-associated macrophage; TGF- $\beta=$ transforming growth factor beta; TMZ = temozolomide; $\mathrm{T}_{\text {reg }}=$ regulatory $\mathrm{T}$ cell.

SUBMITTED September 15, 2021. ACCEPTED November 16, 2021.

INCLUDE WHEN CITING DOI: 10.3171/2021.11.FOCUS21556. 
Multiple mouse GBM models have been developed to understand the immune interactions within the tumor microenvironment. Glioma induction can be accomplished in 4 ways: 1) implantation of syngeneic primary tumor cells into immunocompetent host mice (syngeneic model), 2) xenografts of human glioma cells implanted into immunocompromised mice (patient-derived xenograft [PDX]), 3) xenografts from GBM cell lines implanted into immunocompromised mice, or 4) implantation of genetically modified cells (genetically engineered model). ${ }^{12}$ Idealistically, a perfect animal model is one in which the host immune cells interact with the tumor microenvironment in an identical manner to that of the human immune system, although significant heterogeneity of tumor microenvironments in human malignancies complicates this goal. ${ }^{13,14}$ The greatest advantages of syngeneic murine models over other murine glioma models is the retention of host immunocompetence and recapitulation of the biological and histological features of GBM.12 However, syngeneic models are not infallible, and murine models developed via PDX or genetically engineered techniques are advantageous in certain situations. PDX models are used extensively in translational research studies given their advantage of retaining both the histological and genetic features of the deriving tumor. Genetically engineered models, on the other hand, are often used for testing therapeutic strategies, as they give researchers the ability to pinpoint genetic alterations involved in tumorigenesis and progression. ${ }^{12}$ In this review, we will discuss the most common syngeneic murine glioma models and evaluate key immunological considerations.

\section{GL261 Cells in the C57BL/6 Model}

In 1970, Seligman et al. induced the first GL261 murine model through intracranial implantation of a methylcholanthrene pellet. ${ }^{15}$ Subsequently, Ausman et al. transplanted tumor fragments $\left(1 \times 10^{5}\right.$ tumor cells/10 $\left.\mu \mathrm{l}\right)$ directly into the intracranial space of C57BL/6 mice, resulting in $99.1 \%$ tumor induction with a median survival of 22.1 to 25.9 days and with histological stability for more than 100 generations. ${ }^{16}$ Since its development, the GL261 model has been one of the most commonly used and studied murine GBM models.

Histologically, GL261 gliomas closely resemble human GBMs, demonstrating anaplasia, pleomorphic cells with atypical nuclei, and high mitotic activity. Pseudopallisading necrosis has been seen in GL261 gliomas but not as prominently as in human gliomas. They stain positive for glial fibrillary acidic protein (GFAP) and S100 protein. ${ }^{17}$ GL261 tumors harbor genetic alterations similar to those seen in human GBM. ${ }^{18,19}$ Szatmári et al. demonstrated the presence of an upregulating p53 mutation along with $K$ ras oncogene mutations resulting in increased activated c-myc. ${ }^{20}$ Additional upregulation of the $\mathrm{PI}_{3} \mathrm{~K}$ pathway with secondary PTEN downregulation has been identified. ${ }^{17,21-24}$

Support for using a GL261 glioma model as a preclinical model for therapeutic trials stems from the comprehensive knowledge of the model's characteristics. Stages of tumor progression and growth have been well described, facilitating accurate interpretation of results and extrapolation to potential therapeutic responses. ${ }^{17,25}$ Given its long history as the standard model for immunotherapeutic testing, the GL261 model has been used with high rates of success and efficacy in the preclinical evaluation of dendritic cell vaccines by enhancing immune responses to tumor antigens. GL261 has a uniquely high neoantigen load along with a number of tumor antigens that include HMP/AN2, EphA-2, and GARC-1, lending the model to be uniquely positioned to test potential immunotherapeutic approaches. ${ }^{24,26}$

The similarities between GL261 mice and patients with GBM were reinforced through similarly poor responses to anti-PD-L1 therapy with concurrent dexamethasone. . $8,27,28^{2}$ GL261 mice treated with both anti-PD-L1 therapy and dexamethasone had poor mortality outcomes, similar to the response in humans. Decreased CD4+ and CD8+ T cells in the GL261 mice suggests that concurrent corticosteroid administration diminishes the antitumor immune response. ${ }^{28}$ The standard addition of dexamethasone to patients with GBM produces further corticosteroid-induced immunosuppression, potentially complicating the success of immunotherapeutic agents. ${ }^{29}$ The immunological profile of GL261 has been complicated by the recent advent of luciferase-expressing cell lines such as GL261-Luc2 and GL261 Red-FLuc. ${ }^{27,30,31}$ Luc2 expression may prime GL261 gliomas to immunotherapeutic agents by increasing proinflammatory modulators within the tumor microenvironment, more so than seen in clinical trials. ${ }^{31}$

Despite its strengths, GL261 is limited by its poor immunological translatability from murine to human clinical trials. A likely contributor to the poor translatability of GL261 to human trials is its very high mutational load compared with what is typically observed in human GBM. ${ }^{32,33}$ A high mutational load increases the glioma's sensitivity to checkpoint blockade immunotherapy such as anti-PD-L1 therapy. ${ }^{18,34,35}$ As such, numerous studies have demonstrated the efficacy of various checkpoint inhibitors in GL261 gliomas that did not correlate with treatment responses in human GBM. ${ }^{28,32,36}$ Furthermore, from a therapeutic perspective, the high intrinsic radiosensitivity of GL261 in vitro does not correlate well with the lower sensitivity observed in vivo. ${ }^{20}$

\section{GL261 C57BL/6 Model Immunological Considerations}

GL261 is highly immunogenic with constitutive expression of MHC I but minimal expression of MHC II, B7-1, and B7-2 (the latter two are required for T-cell stimulation). ${ }^{1,20,32,37}$ This contrasts the constitutive downregulation of MHC I and II seen in human GBM. ${ }^{38}$ MHC I and B7 costimulatory molecule expression render tumor cells more susceptible to MHC-dependent cytotoxic T-cell recognition and antigen presentation. ${ }^{20}$ The low expression of MHC II molecules aids in the suppression of antigen presentation to CD4+ T cells (Table 1). ${ }^{39}$

In 2020, Ayasoufi et al. established systemic immunological similarities between GL261 gliomas and human GBM. ${ }^{8}$ Similar to patients with GBM, thymic and splenic involution was directly correlated to the glioma burden in GL261 mice. Furthermore, mice that harbored GL261 gliomas demonstrated peripheral immunosuppres- 
TABLE 1. Overall immune characteristics of syngeneic murine GBM models

\begin{tabular}{lcccc}
\hline & GL261 & SB28 & CT-2A & SMA-560 \\
\hline Overall immunogenicity & High & Low & Low & Moderate \\
\hline MHC class I & High & None & Low & Low \\
\hline MHC class II & Low/none & None & Low & None \\
\hline PD-L1 & Present & Present & Present & Present \\
\hline PD-L2 & None & Unknown & Unknown & Unknown \\
\hline Mutational load & Very high & Low & Moderate & High \\
\hline
\end{tabular}

PD-L2 = programmed death-ligand 2.

sion through reduced CD4+ and CD8+ T cells. MHC II expression declined with increasing GL261 tumor burden, adding credence to a potential role for MHC II-dependent immunosuppression in GBM. ${ }^{7,8,40}$

Additionally, GL261 gliomas have the ability to induce robust recruitment of $\mathrm{T}_{\text {reg }}$ cells and evade physiological antitumor responses. ${ }^{41}$ Given GL261's intrinsic lack of PTEN, it has been used extensively in establishing the role of the programmed cell death protein 1 (PD-1)/PD-L1 axis in GBM. ${ }^{1,32}$ When exposed to anti-PD-L1 and cytotoxic Tlymphocyte associated protein 4 (CTLA-4) blocking antibodies, GL261 tumors were highly sensitive to treatment and $>50 \%$ of treated mice demonstrated long-term survival. $^{32,41,42}$ Furthermore, Wainwright et al. demonstrated that inhibition of indoleamine 2,3-dioxygenase, CTLA-4, and PD-L1 in GL261 mice decreased tumor-infiltrating $\mathrm{T}_{\text {reg }}$ cells, coinciding with a significant increase in T-cellmediated long-term survival. ${ }^{41}$

Although $\mathrm{T}_{\text {reg }}$ cells play a major role in the GBM tumor microenvironment, a higher burden of M2 macrophages and myeloid-derived suppressor cells have been identified compared with the $\mathrm{T}_{\text {reg }}$ burden within GL261 gliomas. Following inoculation, GL261 mice demonstrated concomitant decreases in plasma cytokine levels with increases in CD8+ T cells and natural killer cells within the tumor. ${ }^{43}$ Another factor, CXCL10, which is released in response to interferon- $\gamma$ and TNF- $\alpha$, has been identified as a marker of tumor progression in high-grade gliomas..$^{11,36,44}$ Plasmid vectors expressing CXCL10 have demonstrated efficacy in attenuating GL261 progression likely due to cytokinemediated immunostimulation. ${ }^{45}$

Ultimately, GL261 has been thoroughly studied, and its immunological characteristics are well known. However, its use in preclinical immunotherapeutic trials may be limited due to its increased sensitivity to these immunotherapeutic agents when compared with that of the human GBM paradigm. ${ }^{31}$ A less immunogenic model may be advantageous over the GL261 glioma for immunological evaluation. ${ }^{46}$

\section{SB28 Cells in the C57BL/6 Model}

Given the poor immunogenicity and immunosuppressive tumor microenvironment in human GBM, developing a similar nonimmunogenic murine model is key to evaluating the true efficacy of immunotherapeutic agents. ${ }^{46}$ Developed through transfection of the Sleeping Beauty
(SB) transposon-flanked proto-oncogene, the SB28 cell line was initially induced in a neonatal C57BL/6 mouse. ${ }^{11}$ Since the model is driven by transfection of the human oncogene short hairpin targeting P53, PDGFB, and NRAS, it bears genetic resemblance to the group of GBMs once defined as proneural. ${ }^{11,47} \mathrm{SB} 28$ has been recently evaluated in an effort to establish its similarities and differences to more well-established models such as GL261, although a paucity of evidence remains regarding its immunological profile.

Histologically, SB28 gliomas demonstrate hypervascularization and high cellularity within the tumor borders, along with invasion of normal surrounding brain parenchyma. Scattered and highly heterogeneous T-cell infiltration is observed throughout the tumor in immunocompetent murine models. ${ }^{32}$ Tumor establishment is reliable and effective for SB28 gliomas with a 100\% tumor induction rate and an untreated median survival of 29 days, which offers adequate time for experimentation and evaluation..$^{32}$ In contrast to GL261, SB28 gliomas possess a lower mutational load, lending to a more accurate representation of human GBM along with a more accurate response to potential immunotherapeutic agents in preclinical trials. ${ }^{32}$ This increased accuracy is likely due to the inverse relationship seen between tumor mutational load and clinical responses to immune checkpoint blockade therapy. ${ }^{33,35,48,49}$

\section{SB28 C57BL/6 Model Immunological Considerations}

Compared with GL261, which is highly immunogenic, SB28 has a modest immune profile, lending it to model a more accurate tumor microenvironment. ${ }^{32}$ As described previously, MHC I expression is closely tied to the model's inherent immunogenicity. In contrast to GL261, SB28 is constitutively MHC I negative. MHC II expression was not inducible by interferon- $\gamma$ in SB28 (Table 1). PD-L1 is inducible in SB28 along with expression of CD80, a ligand for the CTLA-4 receptor. ${ }^{32,50}$ In a study exploring the response of dual anti-PD-1 and anti-CTLA-4 blocking antibody therapy, $>50 \%$ of the GL261 mice were longterm survivors. However, no SB28 mice exhibited curative treatment or survival benefit. ${ }^{32,41,42}$ While mutational load is only one factor, given the proximity of SB28 to the median human GBM mutational rate, it could be reasonably inferred that the reduced response to checkpoint blockade therapy seen in SB28 may be more representative of human GBM. ${ }^{32}$

Due to the poor response of SB28 to checkpoint blockade immunotherapy, there has been a recent push to develop various techniques to sensitize murine glioma models to immunotherapeutics. The sodium/hydrogen exchanger 1 (NHE1) protein plays a role in glioma proliferation and invasion. ${ }^{51-53}$ Greater NHE1 expression has been implicated as an independent factor for poor prognosis in GBM..$^{53,54}$ Guan et al. demonstrated that while TMZ therapy alone increased NHE1 expression within the glioma, combining TMZ with an NHE1 inhibitor resulted in attenuation of glioma proliferation and growth..$^{55}$ Triple therapy using TMZ, NHE1 inhibitor, and an anti-PD-1 agent has resulted in significant survival benefits (71\% and $74 \%$ increased median survival, respectively) in both GL261 and SB28. ${ }^{55}$

The SB28 model has also been employed to further 
understand the role of T-cell responses and TAMs in the context of gliomas. Kosaka et al. evaluated the role of antiglioma T-cell activity in the context of anti-CD40 monoclonal antibody combination therapy with the COX-2 inhibitor, celecoxib. ${ }^{11}$ While SB28 did not express CD40, the authors found that combination therapy resulted in regression of the pathological M2-driven tumor microenvironment to an M1-predominant landscape. Anti-CD40 therapy is thought to induce antitumor effects through the activation of CD8+ T cells, natural killer cells, and macrophages. ${ }^{11,56-60}$ Combination therapy significantly increased CXCL10 expression with a corresponding increase in CD8+ T-cell tumor infiltrate. ${ }^{11}$ While recent studies have shown a disconnect between the response of CXCL10 expression in GL261 compared with human high-grade gliomas, there is a relative lack of information regarding the immune profile of SB28. ${ }^{11,36}$

\section{CT-2A Cells in the C57BL/6 Model}

CT-2A was developed through intracranial implantation of methylcholanthrene pellets in immunocompetent C57BL/6 mice. The CT-2A cell line is $100 \%$ tumorigenic with a $100 \%$ mortality rate within 3 to 8 weeks of tumor development. ${ }^{1,61,62}$ Initially described as soft, noncohesive, and highly hemorrhagic, CT-2A gliomas have distinct histological features including high cellular density, pseudopallisading necrosis, and irregularly shaped cells with high and abnormal mitotic activity., ${ }^{1,61}$ CT-2A cells stain positive for p53, GFAP, Sox9, and Sox $10 .^{62}$

Similar to human GBM, CT-2A gliomas are highly proliferative and infiltrative. ${ }^{24,63} \mathrm{CT}-2 \mathrm{~A}$ cells share features with CD133+ brain tumor stem cells (BTSCs) that are capable of self-replication and profound tumor-forming abilities. ${ }^{1,63}$ From a histological and immunological perspective, induction of CT-2A gliomas through neurosphere introduction produced a more aggressive tumor. ${ }^{64}$ Studies in human GBM have established an inverse relationship between CD133+ BTSCs and GBM progression-free survival and overall survival. ${ }^{65}$ CT-2A harbors a genetic mutational burden between SB28 and GL261, yet this is still significantly higher than most human GBM. ${ }^{19,32}$ While CT-2A gliomas do not precisely replicate the human GBM phenotype, they are effective preclinical murine models given their shared histological, immunohistochemical, proliferative, and metabolic profiles. ${ }^{1,62}$

\section{CT-2A C57BL/6 Model Immunological Considerations}

CT-2A presents a unique model that aids in understanding the effects of BTSCs on the progression of GBM and its association with the tumor microenvironment given its similarity to human GBM. Common immunological features include a high burden of tumor-infiltrating macrophages (up to $30 \%$ of the tumor burden) and T-cell exhaustion, as identified through decreased T-cell-driven cytokine production. ${ }^{19,66,67}$ However, there is no significant difference in tumor-infiltrating immune cell quantities between CT-2A or GL261 gliomas..$^{19}$ CT-2A gliomas intrinsically lack the PTEN protein and exhibit a greater expression of PD-L1 relative to GL261 gliomas (Table 1).,19

Despite the increased immune checkpoint molecule ex- pression, CT-2A gliomas are more resistant to checkpoint blockade therapy compared with GL261 glioma models. ${ }^{19,68}$ Anti-PD-1 therapy demonstrated a modest number of long-term, CT-2A glioma-bearing survivors, which was improved following the addition of radiotherapy. ${ }^{28} \mathrm{CT}-2 \mathrm{~A}$ mice treated with anti-PD-L1 had modestly improved median survivals (4.5 days greater) in contrast to the $50 \%$ long-term survival rates seen in GL261 mice. ${ }^{19}$

Vaccination therapy has demonstrated limited success thus far, in part due to the need to identify highly immunogenic neoantigens. ${ }^{1}$ Recently, Liu et al. successfully induced long-term survival in $60 \%$ of CT-2A mice following a specific neoantigen vaccine combined with an anti-PD-L1 therapy. ${ }^{19}$ The high mutational burden of CT2A complicates identification and development of a neoantigen vaccine.

Oncolytic viral therapy has also been investigated in CT-2A mice with positive responses. Barnard et al. demonstrated improved survival in CT-2A mice following treatment with oncolytic herpes simplex virus 1 vectors expressing FMS-like tyrosine kinase 3 ligand (Flt3L). ${ }^{69}$ Treated mice exhibited increased numbers of immature dendritic cells, cytotoxic T lymphocytes, and cytokine expression within the glioma. Ultimately, CT-2A is a poorly immunogenic murine model that is of key use in the understanding of BTSCs in glioma progression and the tumor microenvironment.

\section{SMA-560 Cells in the VM/Dk Model}

In 1971, Fraser described the first spontaneously developing murine glioma model in VM/Dk mice. ${ }^{70}$ Histologically, these in vivo tumors exhibit small, hyperchromatic nuclei and occasional mitotic figures. Furthermore, they are highly cellular with sporadic areas of focal necrosis and vascular proliferation. ${ }^{71}$ Due to a loss in tumorigenicity, a transfected tumor, P560, was developed that was histologically indistinguishable from nontransfected tumors. ${ }^{1,71,72}$ SMA-560 demonstrates strong GFAP and glutamine synthetase, but low S100 staining. ${ }^{1,71}$ SMA-560 mice exhibit a median survival of approximately 26 days following induction. ${ }^{72,73}$

The spontaneous development of SMA-560 avoids artifactual antitumor responses to immunotherapeutics due to the mutational load..$^{1,18,32,71}$ However, its widespread use has been significantly limited by its lack of commercial availability. ${ }^{1}$ Given its limited availability, there are significant gaps in the current literature regarding its immunological profile.

\section{SMA-560 VM/Dk Model Immunological Considerations}

SMA-560 expresses low baseline levels of MHC I and undetectable levels of MHC II, indicating its potential for T-cell antigenic detection (Table 1). ${ }^{1,71}$ Similar to human GBM, there is increased transforming growth factor beta (TGF- $\beta$ ) expression in SMA-560 gliomas. ${ }^{74}$ TGF- $\beta$ has been implicated in the pathogenesis of GBM by augmenting immunosuppression, proliferation, invasion, and angiogenesis. $1,71,73$

Recently, Papachristodoulou et al. showed the success of an antisense oligonucleotide (ASO) blockade of TGF- $\beta$ 
TABLE 2. Major preclinical applications of syngeneic murine models

\begin{tabular}{|c|c|c|c|c|}
\hline $\begin{array}{l}\text { GBM } \\
\text { Cell Type }\end{array}$ & $\begin{array}{l}\text { Mouse } \\
\text { Species }\end{array}$ & $\begin{array}{l}\text { Authors } \\
\& \text { Year }\end{array}$ & $\begin{array}{l}\text { Preclinical Study } \\
\text { Application }\end{array}$ & $\begin{array}{l}\text { Study Outcome/ } \\
\text { Experimental Implications }\end{array}$ \\
\hline \multirow{3}{*}{ GL261 } & $\mathrm{C} 57 \mathrm{BL} / 6$ & $\begin{array}{l}\text { Genoud et al., 2018; }{ }^{32} \text { Wainwright et al., 2014; } ;^{41} \\
\text { Reardon et al., 2016 }\end{array}$ & $\begin{array}{l}\text { Immune check- } \\
\text { point blockades }\end{array}$ & $\begin{array}{l}\text { - Anti-PD-1 \& anti-CTLA-4 therapy } \\
\cdot>50 \% \text { of treated mice exhibited long-term survival }\end{array}$ \\
\hline & C57BL/6 & Belmans et al., 2017;:24 Haddad et al., $2021^{26}$ & $\begin{array}{l}\text { Dendritic cell vac- } \\
\text { cines }\end{array}$ & $\begin{array}{l}\text { - Intraparenchymal dendritic cells pulsed w/ GL261 cell } \\
\text { extracts } \\
\text { - } 60 \% 100 \text {-day survival rate } \\
\text { - Enhanced delayed-type hypersensitivity response w/ } \\
\text { protection against tumor rechallenge }\end{array}$ \\
\hline & C57BL/6 & Enderlin et al., $2009^{45}$ & Plasmid vectors & $\begin{array}{l}\text { - Plasmid vector expressing CXCL10 in vivo } \\
\text { - Attenuation of GL261 progression due to cytokine- } \\
\text { mediated immunostimulation }\end{array}$ \\
\hline \multirow[b]{2}{*}{ SB28 } & $\mathrm{C} 57 \mathrm{BL} / 6$ & $\begin{array}{l}\text { Genoud et al., 2018; } 32 \text { Wainwright et al., } \\
2014 ; ;^{41} \text { Reardon et al., } 2016^{42}\end{array}$ & $\begin{array}{l}\text { Immune check- } \\
\text { point blockades }\end{array}$ & $\begin{array}{l}\text { - Anti-PD-1 \& anti-CTLA-4 therapy } \\
\text { - No curative or survival benefit }\end{array}$ \\
\hline & $\mathrm{C} 57 \mathrm{BL} / 6$ & $\begin{array}{l}\text { Kosaka et al., 2014;11 Todryk et al., 2001;56 } \\
\text { Turner et al., 2001;57 van Mierlo et al., 2002;58 } \\
\text { Lum et al., 2006; }{ }^{59} \text { Beatty et al., } 2011^{60}\end{array}$ & $\begin{array}{l}\text { Anti-CD40 ther- } \\
\text { apy }\end{array}$ & $\begin{array}{l}\text { - Induction of CD8+ T cells, NK cells, \& macrophages } \\
\text { - Resultant antitumor effects }\end{array}$ \\
\hline \multirow[b]{2}{*}{ CT-2A } & C57BL/6 & $\begin{array}{l}\text { Liu et al., } 2020 ;{ }^{19} \text { lorgulescu et al., 2021:28 } \\
\quad \text { Nakashima et al., } 2018^{68}\end{array}$ & $\begin{array}{l}\text { Immune check- } \\
\text { point blockades }\end{array}$ & $\begin{array}{l}\text { - CT-2A mice treated w/ anti-PD-L1 } \\
\text { - Modestly improved survival (+4.5 days) in CT-2A, com- } \\
\quad \text { pared w/ 50\% long-term survival in GL261 }\end{array}$ \\
\hline & C57BL/6 & Barnard et al., $2012^{69}$ & $\begin{array}{l}\text { Oncolytic viral } \\
\text { vectors }\end{array}$ & $\begin{array}{l}\text { - Direct inoculation oncolytic herpes simplex virus } 1 \text { vec- } \\
\text { tor expressing Flt3L } \\
\text { - Improved immature dendritic cells, CTLs, \& cytokine } \\
\text { expression w/in the tumor }\end{array}$ \\
\hline \multirow{4}{*}{ SMA-560 } & VM/Dk & Heimberger et al., $2000^{73}$ & $\begin{array}{l}\text { Dendritic cell } \\
\text { systemic vac- } \\
\text { cination }\end{array}$ & $\begin{array}{l}\text { - Systemic vaccination w/ bone marrow-derived dendritic } \\
\text { cells pulsed w/ SMA-560 homogenate } \\
\cdot>160 \% \text { increase in median survival compared w/ } \\
\text { untreated mice }\end{array}$ \\
\hline & VM/Dk & Haddad et al., $2021^{26}$ & CAR T cells & $\begin{array}{l}\text { - CAR T cells specific for EGFRvIll } \\
\text { - Improved survival \& cure of intracranial tumor w/ protec- } \\
\text { tion against tumor rechallenge }\end{array}$ \\
\hline & VM/Dk & Haddad et al., $2021^{26}$ & Soluble CD70 & $\begin{array}{l}\text { - Soluble CD70 in vitro } \\
\text { - Improved } 60 \text {-day survival increase in treated mice from } \\
5 \% \text { to } 45 \% \\
\text { - Enhanced proliferation \& IFN- } \gamma \text { of syngeneic spleno- } \\
\text { cytes }\end{array}$ \\
\hline & VM/Dk & Papachristodoulou et al., $2019^{74}$ & ASO blockade & $\begin{array}{l}\text { - ASO blockade of TGF- } \beta \text { reduced in vitro tumor invasion } \\
\text { \& migration } \\
\text { - Increased immune cell burden \& reduced vascularity } \\
\text { in vivo }\end{array}$ \\
\hline
\end{tabular}

CAR T cell = chimeric antigen receptor T cell; CTL = cytotoxic T lymphocyte; EGFRvIII = epidermal growth factor variant III; Flt3L = FMS-like tyrosine kinase 3 ligand; IFN- $\gamma=$ interferon gamma; $\mathrm{NK}=$ natural killer.

in vivo and in vitro. ${ }^{74}$ TGF- $\beta$ inhibition reduced in vitro invasion and migration of SMA-560 cells. In an in vivo model, treated SMA-560 mice had an increased immune cell burden with a concomitant decrease in vascularity.

The SMA-560 model has been used to investigate potential tumor vaccines. Heimberger et al. revealed the efficacy of systemic vaccination with bone marrow-derived dendritic cells pulsed with SMA-560 homogenate in producing long-term survival in mice bearing SMA-560 gliomas. ${ }^{73}$ Both cellular and humoral immune responses were identified, and these mice demonstrated long-term survival following tumor reimplantation, which indicated immunological memory. Furthermore, SMA-560 has been used for the evaluation of chimeric antigen receptor $\mathrm{T}$ cells that are specific for epidermal growth factor receptor vIII, which has demonstrated curative capabilities in intracranial tumors that are resistant to tumor rechallenge. ${ }^{26}$ Soluble CD70, an activator of the costimulatory receptor CD27, has also been tested utilizing SMA-560 gliomas and has shown improved survival in VM/Dk mice following therapy. ${ }^{26}$

\section{Discussion}

As immunotherapeutic agents are developed, animal models will continue to play a crucial role during the pre- 

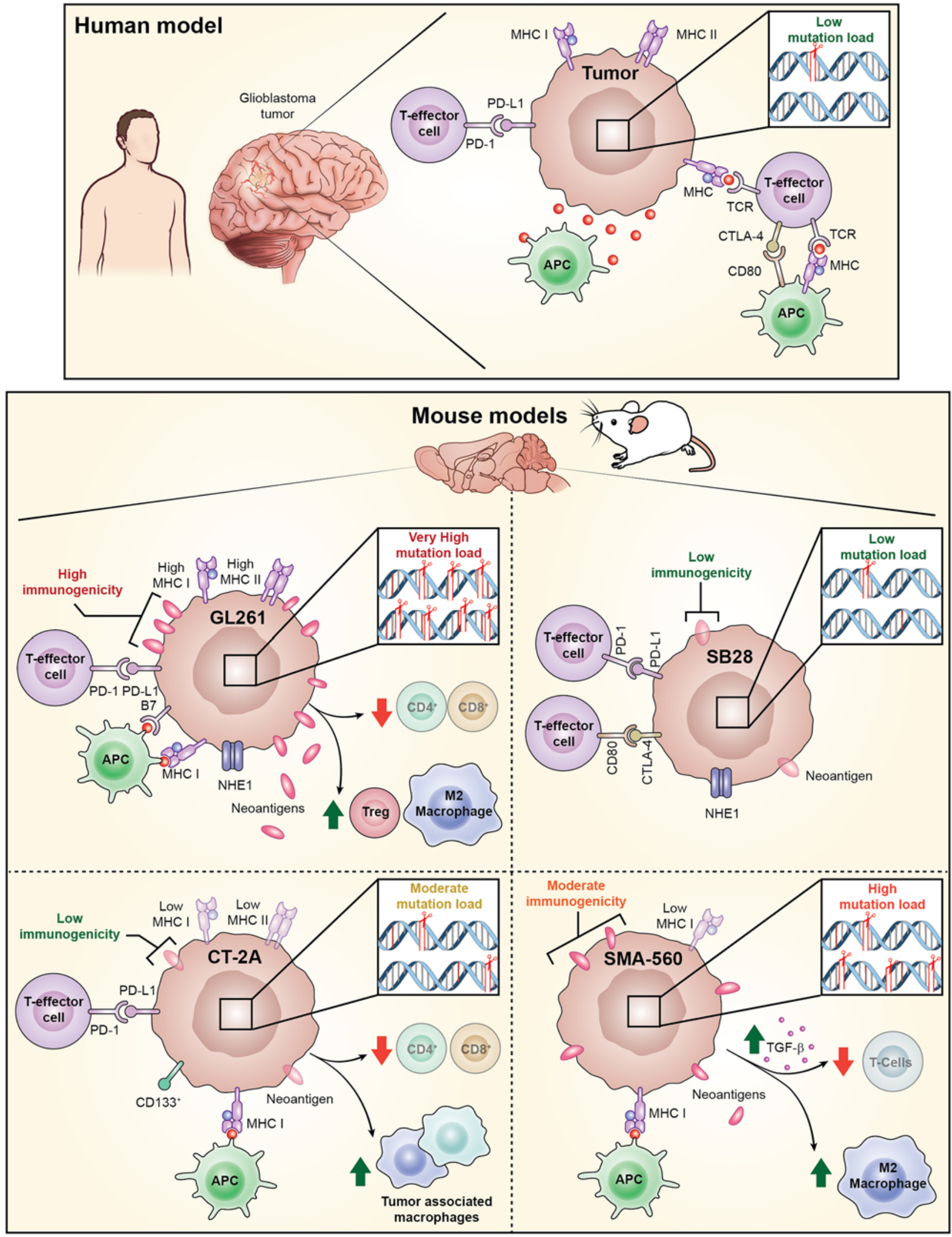

FIG. 1. Immunological profile of human GBM and murine glioma models. The GBM microenvironment exhibits an intricate relationship between the highly immunosuppressive tumor cells and host immune cells. Upper: Illustration showing the interaction between the tumor cell and the human immune system. PD-L1 is expressed by tumor cells and inhibits T cells by binding to T-cell PD-1 receptors. FIG. 1 (continued) $\rightarrow$ 
FIG. 1. Tumor antigens are taken up by antigen-presenting cells, which subsequently prime $T$ cells in a highly regulated interaction involving costimulatory (CD80) and coinhibitory (CTLA-4) immune checkpoint modulators. Lower: Illustration depicting the similarities and differences between the 4 murine glioma models and human GBM. Relative immunogenicity is characterized by each murine model's relationship to human GBM. APC $=$ antigenpresenting cell; TCR = T-cell receptor. Illustration from the National Institute of Neurological Disorders and Stroke, National Institutes of Health.

clinical phases. An important consideration when using syngeneic animal models is the degree of genomic similarity and stability in the highly inbred models. The C57BL/6 mouse possesses a $98 \%$ loci homozygosity within a single generation; therefore, individuals within a single generation are virtually genetically identical. Practices such as careful breeding, cryoarchiving, and frequent sequencing are key steps in ensuring the reproducibility of studies involving syngeneic models. ${ }^{75}$

While GL261 has been frequently used in murine studies for GBM treatment, it is highly immunogenic and has an extremely high mutational load resulting in an unpredictable response to immunotherapeutic agents in clinical trials. ${ }^{8,31,41}$ However, GL261 has been well characterized, yielding it a predictable model for testing. ${ }^{\text {S SB2 } 8} 8$ is a poorly immunogenic murine model that has shown potential from an immunological standpoint given the similarity of its tumor microenvironment to that of human GBM. As such, SB28 may be a reliable model for preclinical testing and tumor microenvironment characterization. ${ }^{32} \mathrm{CT}-2 \mathrm{~A}$ is poorly immunogenic; however, there is a relative paucity of information regarding its immunological profile, and recent studies have been implementing this cell line more frequently. ${ }^{63,64}$ Finally, SMA-560 is a moderately immunogenic model with a high mutational load predisposing it to unpredictable responses to immunotherapeutics; however, it has fallen out of popularity due to the advent of newer tumorigenic cell lines., ${ }^{1,73,74}$ Despite the strengths of syngeneic murine GBM models, there are inherent limitations that are addressed by other models. For example, PDX models are advantageous in translational research studies given their retention of the histological and genetic features of the deriving tumor. This faithful recapitulation of human GBM characteristics following orthotopic injection into mice lends a significant advantage of PDX models over syngeneic models. However, this benefit must be weighed with the knowledge that as each PDX model is derived from a unique patient sample, there is significant heterogeneity between individual PDX models. From an immunological standpoint, PDX models are currently established in immunodeficient mice, which complicates the investigation into the role of the immune system in the GBM microenvironment. ${ }^{26}$ Hence, potential therapeutics should be evaluated in multiple murine models to better assess the translatability of results, given the limitations of each individual model (Table 2).

\section{Conclusions}

Syngeneic murine models allow for rapid tumor implantation with reliable tumor growth and characteristics throughout multiple generations and experiments. Despite their clear strengths, care must be taken to choose the most appropriate model for the intended purpose. The immunocompetent murine GBM models reviewed in this article all resemble certain biological and immunologi- cal features seen in human GBM, allowing for translatable results from murine to human trials (Fig. 1). While the immunological profile of GL261 is well characterized, recent studies have revealed limitations to its immunological similarity to human GBM. Other newer, less immunogenic cell lines such as CT-2A and SB28 may be better candidates to study GBM-induced immunosuppression, although further research is necessary. The use of in vivo models, including humanized murine models, is likely to expand as the push for multimodal therapies accelerates in the race to improve survival in patients with GBM.

\section{References}

1. Oh T, Fakurnejad S, Sayegh ET, et al. Immunocompetent murine models for the study of glioblastoma immunotherapy. J Transl Med. 2014;12:107.

2. Batash R, Asna N, Schaffer P, Francis N, Schaffer M. Glioblastoma multiforme, diagnosis and treatment; recent literature review. Curr Med Chem. 2017;24(27):3002-3009.

3. Tykocki T, Eltayeb M. Ten-year survival in glioblastoma. A systematic review. J Clin Neurosci. 2018;54:7-13.

4. Cheema TA, Wakimoto H, Fecci PE, et al. Multifaceted oncolytic virus therapy for glioblastoma in an immunocompetent cancer stem cell model. Proc Natl Acad Sci U S A. 2013; 110(29):12006-12011.

5. Tan AC, Ashley DM, López GY, Malinzak M, Friedman HS, Khasraw M. Management of glioblastoma: state of the art and future directions. CA Cancer J Clin. 2020;70(4):299-312.

6. Nduom EK, Weller M, Heimberger AB. Immunosuppressive mechanisms in glioblastoma. Neuro Oncol. 2015;17(suppl 7): vii9-vii14.

7. Chongsathidkiet $P$, Jackson C, Koyama S, et al. Sequestration of $\mathrm{T}$ cells in bone marrow in the setting of glioblastoma and other intracranial tumors. Nat Med. 2018;24(9):1459-1468.

8. Ayasoufi K, Pfaller CK, Evgin L, et al. Brain cancer induces systemic immunosuppression through release of non-steroid soluble mediators. Brain. 2020;143(12):3629-3652.

9. Allavena P, Mantovani A. Immunology in the clinic review series; focus on cancer: tumour-associated macrophages: undisputed stars of the inflammatory tumour microenvironment. Clin Exp Immunol. 2012;167(2):195-205.

10. Khaled YS, Ammori BJ, Elkord E. Myeloid-derived suppressor cells in cancer: recent progress and prospects. Immunol Cell Biol. 2013;91(8):493-502.

11. Kosaka A, Ohkuri T, Okada H. Combination of an agonistic anti-CD40 monoclonal antibody and the COX-2 inhibitor celecoxib induces anti-glioma effects by promotion of type-1 immunity in myeloid cells and T-cells. Cancer Immunol Immunother. 2014;63(8):847-857.

12. Kijima N, Kanemura Y. Mouse models of glioblastoma. In: De Vleeschouwer S, ed. Glioblastoma. Codon Publications; 2017.

13. Fridman WH, Pagès F, Sautès-Fridman C, Galon J. The immune contexture in human tumours: impact on clinical outcome. Nat Rev Cancer. 2012;12(4):298-306.

14. Ngiow SF, Loi S, Thomas D, Smyth MJ. Mouse models of tumor immunotherapy. Adv Immunol. 2016;130:1-24.

15. Seligman AM, Shear MJ, Alexander L. Studies in carcinogenesis: VIII. Experimental production of brain tumors in mice with methylcholanthrene. Am J Cancer. 1939;37(3): 364-395. 
16. Ausman JI, Shapiro WR, Rall DP. Studies on the chemotherapy of experimental brain tumors: development of an experimental model. Cancer Res. 1970;30(9):2394-2400.

17. Newcomb EW, Zagzag D. The murine GL261 glioma experimental model to assess novel brain tumor treatments. In: Meir EG, ed. CNS Cancer. Humana Press; 2009:227-241.

18. Johanns TM, Ward JP, Miller CA, et al. Endogenous neoantigen-specific CD8 T cells identified in two glioblastoma models using a cancer immunogenomics approach. Cancer Immunol Res. 2016;4(12):1007-1015.

19. Liu CJ, Schaettler M, Blaha DT, et al. Treatment of an aggressive orthotopic murine glioblastoma model with combination checkpoint blockade and a multivalent neoantigen vaccine. Neuro Oncol. 2020;22(9):1276-1288.

20. Szatmári T, Lumniczky K, Désaknai S, et al. Detailed characterization of the mouse glioma 261 tumor model for experimental glioblastoma therapy. Cancer Sci. 2006;97(6): 546-553.

21. Trent J, Meltzer P, Rosenblum M, et al. Evidence for rearrangement, amplification, and expression of c-myc in a human glioblastoma. Proc Natl Acad Sci U S A. 1986;83(2): 470-473.

22. Sidransky D, Mikkelsen T, Schwechheimer K, Rosenblum ML, Cavanee W, Vogelstein B. Clonal expansion of p53 mutant cells is associated with brain tumour progression. Nature. 1992;355(6363):846-847.

23. Gururaj AE, Gibson L, Panchabhai S, et al. Access to the nucleus and functional association with c-Myc is required for the full oncogenic potential of $\triangle \mathrm{EGFR} / \mathrm{EGFRvIII} . J \mathrm{Biol}$ Chem. 2013;288(5):3428-3438.

24. Belmans J, Van Woensel M, Creyns B, Dejaegher J, Bullens DM, Van Gool SW. Immunotherapy with subcutaneous immunogenic autologous tumor lysate increases murine glioblastoma survival. Sci Rep. 2017;7(1):13902.

25. Zagzag D, Amirnovin R, Greco MA, et al. Vascular apoptosis and involution in gliomas precede neovascularization: a novel concept for glioma growth and angiogenesis. $L a b$ Invest. 2000;80(6):837-849.

26. Haddad AF, Young JS, Amara D, et al. Mouse models of glioblastoma for the evaluation of novel therapeutic strategies. Neurooncol Adv. 2021;3(1):vdab100.

27. Zeng J, See AP, Phallen J, et al. Anti-PD-1 blockade and stereotactic radiation produce long-term survival in mice with intracranial gliomas. Int J Radiat Oncol Biol Phys. 2013; 86(2):343-349.

28. Iorgulescu JB, Gokhale PC, Speranza MC, et al. Concurrent dexamethasone limits the clinical benefit of immune checkpoint blockade in glioblastoma. Clin Cancer Res. 2021;27(1): 276-287.

29. Daubon T, Hemadou A, Romero Garmendia I, Saleh M. Glioblastoma immune landscape and the potential of new immunotherapies. Front Immunol. 2020;11:585616.

30. Belcaid Z, Phallen JA, Zeng J, et al. Focal radiation therapy combined with 4-1BB activation and CTLA-4 blockade yields long-term survival and a protective antigen-specific memory response in a murine glioma model. PLoS One. 2014;9(7):e101764.

31. Sanchez VE, Lynes JP, Walbridge S, et al. GL261 luciferaseexpressing cells elicit an anti-tumor immune response: an evaluation of murine glioma models. Sci Rep. 2020;10(1): 11003.

32. Genoud V, Marinari E, Nikolaev SI, et al. Responsiveness to anti-PD-1 and anti-CTLA-4 immune checkpoint blockade in SB28 and GL261 mouse glioma models. Oncoimmunology. 2018;7(12):e1501137.

33. Touat M, Li YY, Boynton AN, et al. Mechanisms and therapeutic implications of hypermutation in gliomas. Nature. 2020;580(7804):517-523.

34. Le DT, Uram JN, Wang H, et al. PD-1 blockade in tumors with mismatch-repair deficiency. N Engl J Med. 2015; 372(26):2509-2520.

35. Llosa NJ, Cruise M, Tam A, et al. The vigorous immune microenvironment of microsatellite instable colon cancer is balanced by multiple counter-inhibitory checkpoints. Cancer Discov. 2015;5(1):43-51.

36. Xue W, Zhang J, Tong H, et al. Effects of BMPER, CXCL10, and HOXA9 on neovascularization during early-growth stage of primary high-grade glioma and their corresponding MRI biomarkers. Front Oncol. 2020;10:711.

37. Maes W, Van Gool SW. Experimental immunotherapy for malignant glioma: lessons from two decades of research in the GL261 model. Cancer Immunol Immunother. 2011;60(2): 153-160.

38. Wu A, Wiesner S, Xiao J, et al. Expression of MHC I and NK ligands on human CD133+ glioma cells: possible targets of immunotherapy. J Neurooncol. 2007;83(2):121-131.

39. Soos JM, Krieger JI, Stüve O, et al. Malignant glioma cells use MHC class II transactivator (CIITA) promoters III and IV to direct IFN-gamma-inducible CIITA expression and can function as nonprofessional antigen presenting cells in endocytic processing and CD4(+) T-cell activation. Glia. 2001; 36(3):391-405.

40. Gustafson MP, Lin Y, New KC, et al. Systemic immune suppression in glioblastoma: the interplay between CD14+HLADRlo/neg monocytes, tumor factors, and dexamethasone. Neuro Oncol. 2010;12(7):631-644.

41. Wainwright DA, Chang AL, Dey M, et al. Durable therapeutic efficacy utilizing combinatorial blockade against IDO, CTLA-4, and PD-L1 in mice with brain tumors. Clin Cancer Res. 2014;20(20):5290-5301.

42. Reardon DA, Gokhale PC, Klein SR, et al. Glioblastoma eradication following immune checkpoint blockade in an orthotopic, immunocompetent model. Cancer Immunol Res. 2016;4(2):124-135.

43. McKelvey KJ, Hudson AL, Prasanna Kumar R, et al. Temporal and spatial modulation of the tumor and systemic immune response in the murine Gl261 glioma model. PLoS One. 2020;15(4):e0226444.

44. Luster AD, Unkeless JC, Ravetch JV. Gamma-interferon transcriptionally regulates an early-response gene containing homology to platelet proteins. Nature. 1985;315(6021):672676.

45. Enderlin M, Kleinmann EV, Struyf S, et al. TNF-alpha and the IFN-gamma-inducible protein 10 (IP-10/CXCL-10) delivered by parvoviral vectors act in synergy to induce antitumor effects in mouse glioblastoma. Cancer Gene Ther. 2009; 16(2):149-160.

46. Sharma P, Allison JP. The future of immune checkpoint therapy. Science. 2015;348(6230):56-61.

47. Kohanbash G, Carrera DA, Shrivastav S, et al. Isocitrate dehydrogenase mutations suppress STAT1 and CD8+ T cell accumulation in gliomas. J Clin Invest. 2017;127(4):14251437.

48. Segal NH, Parsons DW, Peggs KS, et al. Epitope landscape in breast and colorectal cancer. Cancer Res. 2008;68(3):889892.

49. Rizvi NA, Hellmann MD, Snyder A, et al. Cancer immunology. Mutational landscape determines sensitivity to PD-1 blockade in non-small cell lung cancer. Science. 2015; 348(6230):124-128.

50. Leach DR, Krummel MF, Allison JP. Enhancement of antitumor immunity by CTLA-4 blockade. Science. 1996; 271(5256):1734-1736.

51. McLean LA, Roscoe J, Jorgensen NK, Gorin FA, Cala PM. Malignant gliomas display altered $\mathrm{pH}$ regulation by NHE1 compared with nontransformed astrocytes. Am J Physiol Cell Physiol. 2000;278(4):C676-C688.

52. Cong D, Zhu W, Shi Y, et al. Upregulation of NHE1 protein 
expression enables glioblastoma cells to escape TMZ-mediated toxicity via increased $\mathrm{H}^{+}$extrusion, cell migration and survival. Carcinogenesis. 2014;35(9):2014-2024.

53. Guan X, Luo L, Begum G, et al. Elevated $\mathrm{Na} / \mathrm{H}$ exchanger 1 (SLC9A1) emerges as a marker for tumorigenesis and prognosis in gliomas. J Exp Clin Cancer Res. 2018;37(1):255.

54. Zhu W, Carney KE, Pigott VM, et al. Glioma-mediated microglial activation promotes glioma proliferation and migration: roles of $\mathrm{Na}+/ \mathrm{H}+$ exchanger isoform 1. Carcinogenesis. 2016;37(9):839-851.

55. Guan X, Hasan MN, Begum G, et al. Blockade of $\mathrm{Na} / \mathrm{H}$ exchanger stimulates glioma tumor immunogenicity and enhances combinatorial TMZ and anti-PD-1 therapy. Cell Death Dis. 2018;9(10):1010.

56. Todryk SM, Tutt AL, Green MH, et al. CD40 ligation for immunotherapy of solid tumours. J Immunol Methods. 2001; 248(1-2):139-147.

57. Turner JG, Rakhmilevich AL, Burdelya L, et al. Anti-CD40 antibody induces antitumor and antimetastatic effects: the role of NK cells. J Immunol. 2001;166(1):89-94.

58. van Mierlo GJD, den Boer AT, Medema JP, et al. CD40 stimulation leads to effective therapy of CD40(-) tumors through induction of strong systemic cytotoxic T lymphocyte immunity. Proc Natl Acad Sci U S A. 2002;99(8):5561-5566.

59. Lum HD, Buhtoiarov IN, Schmidt BE, et al. In vivo CD40 ligation can induce T-cell-independent antitumor effects that involve macrophages. J Leukoc Biol. 2006;79(6):1181-1192.

60. Beatty GL, Chiorean EG, Fishman MP, et al. CD40 agonists alter tumor stroma and show efficacy against pancreatic carcinoma in mice and humans. Science. 2011;331(6024): 1612-1616.

61. Seyfried TN, el-Abbadi M, Roy ML. Ganglioside distribution in murine neural tumors. Mol Chem Neuropathol. 1992;17(2): 147-167.

62. Martínez-Murillo R, Martínez A. Standardization of an orthotopic mouse brain tumor model following transplantation of CT-2A astrocytoma cells. Histol Histopathol. 2007;22(12): 1309-1326.

63. Binello E, Qadeer ZA, Kothari HP, Emdad L, Germano IM. Stemness of the CT-2A immunocompetent mouse brain tumor model: characterization in vitro. J Cancer. 2012;3(3): 166-174.

64. Riva M, Wouters R, Weerasekera A, et al. CT-2A neurospheres-derived high-grade glioma in mice: a new model to address tumor stem cells and immunosuppression. Biol Open. 2019;8(9):bio044552.

65. Zeppernick F, Ahmadi R, Campos B, et al. Stem cell marker CD133 affects clinical outcome in glioma patients. Clin Cancer Res. 2008;14(1):123-129.

66. Rosenberg SA, Yang JC, Restifo NP. Cancer immunotherapy: moving beyond current vaccines. Nat Med. 2004;10(9):909915.

67. Woroniecka K, Chongsathidkiet P, Rhodin K, et al. T-cell exhaustion signatures vary with tumor type and are severe in glioblastoma. Clin Cancer Res. 2018;24(17):4175-4186.
68. Nakashima H, Alayo QA, Penaloza-MacMaster P, et al. Modeling tumor immunity of mouse glioblastoma by exhausted CD8 ${ }^{+}$T cells. Sci Rep. 2018;8(1):208.

69. Barnard Z, Wakimoto H, Zaupa C, et al. Expression of FMSlike tyrosine kinase 3 ligand by oncolytic herpes simplex virus type I prolongs survival in mice bearing established syngeneic intracranial malignant glioma. Neurosurgery. 2012;71(3):741-748.

70. Fraser H. Astrocytomas in an inbred mouse strain. J Pathol. 1971;103(4):266-270.

71. Sampson JH, Ashley DM, Archer GE, et al. Characterization of a spontaneous murine astrocytoma and abrogation of its tumorigenicity by cytokine secretion. Neurosurgery. 1997; 41(6):1365-1373.

72. Serano RD, Pegram CN, Bigner DD. Tumorigenic cell culture lines from a spontaneous VM/Dk murine astrocytoma (SMA). Acta Neuropathol. 1980;51(1):53-64.

73. Heimberger AB, Crotty LE, Archer GE, et al. Bone marrowderived dendritic cells pulsed with tumor homogenate induce immunity against syngeneic intracerebral glioma. J Neuroimmunol. 2000;103(1):16-25.

74. Papachristodoulou A, Silginer M, Weller M, et al. Therapeutic targeting of TGF $\beta$ ligands in glioblastoma using novel antisense oligonucleotides reduces the growth of experimental gliomas. Clin Cancer Res. 2019;25(23):7189-7201.

75. Sarsani VK, Raghupathy N, Fiddes IT, et al. The genome of C57BL/6J "Eve", the mother of the laboratory mouse genome reference strain. G3 (Bethesda). 2019;9(6):1795-1805.

\section{Disclosures}

The authors report no conflict of interest concerning the materials or methods used in this study or the findings specified in this paper.

\section{Author Contributions}

Conception and design: Letchuman, Ampie. Acquisition of data: Letchuman, Ampie. Analysis and interpretation of data: Letchuman, Ampie, Shah, Brown. Drafting the article: Letchuman, Ampie, Shah, Brown. Critically revising the article: all authors. Reviewed submitted version of manuscript: all authors. Approved the final version of the manuscript on behalf of all authors: Ampie. Administrative/technical/material support: Heiss, Chittiboina. Study supervision: Heiss, Chittiboina.

\section{Correspondence}

Leonel Ampie: National Institute of Neurological Disorders and Stroke, National Institutes of Health, Bethesda, MD. leonel.ampie@nih.gov. 